\title{
Terza Edizione del Concorso Quirino Maggiore Firenze, 17 ottobre 2021
}

\author{
Marco Lombardi ${ }^{1}$, Leonardo Mari $^{2}$ \\ ${ }^{1}$ Nefrologia \& Dialisi, Ospedale Nuovo del Mugello, Azienda Sanitaria Locale Toscana Centro, Firenze - Italy \\ ${ }^{2}$ Farmacia, Ospedale Nuovo del Mugello, Azienda Sanitaria Locale Toscana Centro, Firenze - Italy
}

Come ormai consuetudine, nella spettacolare Sala D'Arme di Palazzo Vecchio, si è svolta la premiazione della $3^{\text {a }}$ Edizione del Concorso di Narrativa, Poesia e Fotografia in nefrologia, dialisi e trapianto, per persone in cura, famigliari e caregiver e per i professionisti della salute.

Il Covid ci ha obbligato a un'Edizione con presenza ridotta con solo la metà dei posti della Sala occupabile. Per questo motivo, abbiamo rapidamente organizzato la ripresa diretta in rete su YouTube, Facebook e Zoom.

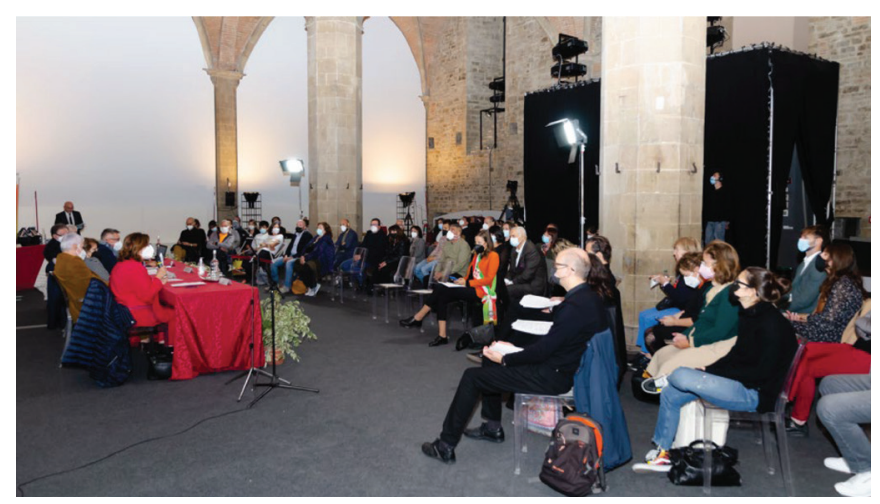

Purtroppo, molti interessati e affezionati parenti e amici dei premiati non hanno potuto presenziare a questa manifestazione emozionante.

La segreteria del concorso, tenuta come sempre in modo ineccepibile ed efficientissimo dalla Sig.ra Francesca Monzecchi, ha super-lavorato per le difficoltà accessorie dovute all'epoca Covid.

Received: November 2, 2021

Accepted: November 2, 2021

Published online: November 18, 2021

Indirizzo per la corrispondenza:

Marco Lombardi

Ospedale del Mugello

Via Della Resistenza, 60

50032 Borgo San Lorenzo, Firenze - Italy

lombardim@tin.i
Garantite le emozioni per tutti; bravissimi come sempre gli attori nel leggere le poesie, un sunto dei racconti di narrativa e i pensieri espressi dai fotografi sulle loro fotografie.

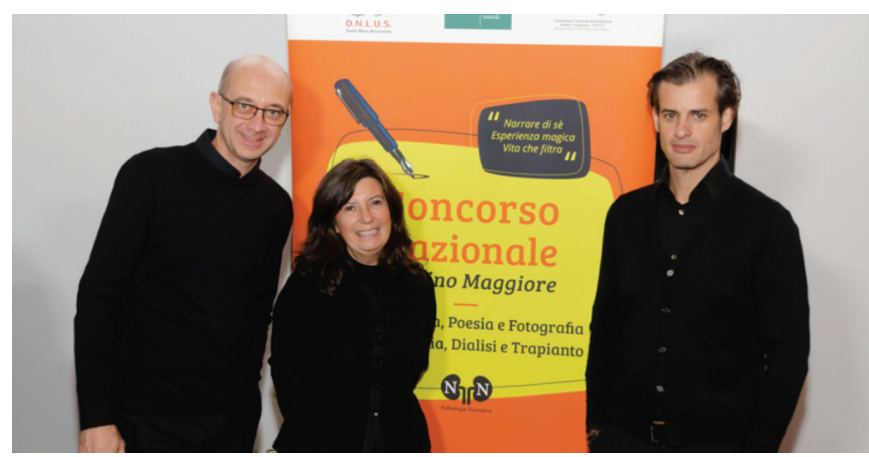

Veramente interessanti i contributi ricevuti, toccanti, per l'abilità di scrivere e per le loro argomentazioni.

Toccante il filmato-testimonianza di un grande paziente, Ivo Feletig, il cui figlio ha ritirato il premio speciale dedicato all'insegnamento che ha dato a tutti i suoi curanti.

Ma inutile, per me, povero ipoalfabetizzato, cercare di esprimere sentimenti che ho provato ma che non riesco a esplicitare.

Lascio farlo a uno che sa tenere la penna in mano con un suo gioiello, che, appunto, parla di Gioielli.

\section{Gioielli}

Luccicanti pietre sgorgano dalla fonte d'eterno dolore. Perle, graffio d'un granello che incista l'anima son la meraviglia del mondo agli occhi dell'uomo. Nient'altro che arte il dolore ammirato, bellissimo grido infinito che separa da Dio.

Leonardo Mari 